\title{
Habit and long memory in UK lottery sales
}

\author{
I.G. McHale ${ }^{\text {a,* }}$, D.A. Peel ${ }^{\text {b }}$ \\ ${ }^{a}$ Centre for the Study of Gambling and Centre for Operations Management, Management Science and Statistics, University of Salford, M5 4WT, UK \\ b Lancaster University Management School, Lancaster, LA1 4YX, UK
}

\section{A R T I C L E I N F O}

\section{Article history:}

Received 29 June 2009

Received in revised form 19 June 2010

Accepted 6 July 2010

Available online 15 July 2010

JEL classification:

$\mathrm{C} 22$

C53

H41

Keywords:

Long memory

Fractional integration

Lottery

\begin{abstract}
A B S T R A C T
Long memory processes can occur as a consequence of aggregation over heterogeneous agents. We examine the UK lottery and, by estimating the level of fractional differencing, find evidence of the long memory property in lottery sales, a result that has broader implications on the estimation of demand models for lotteries.
\end{abstract}

(c) 2010 Elsevier B.V. All rights reserved.

\section{Introduction}

Numerous time series studies have been conducted on the determinants of lottery (Lotto) sales in various countries. (See, for example, Beenstock and Haitovsky, 2001, Cook and Clotfelter, 1993, Walker and Young, 2001, and Forrest et al., 2000). One feature of the reported results is the persistence of lottery sales, as measured by the significance of a number of lags of the dependent variable, given the other determinants such as expected price, other higher moments or jackpot size. For example, Beenstock and Haitovsky (2001), employing Israeli data, report three significant lags which are all positive with declining weights, Forrest et al. (2000) report four positive lags employing UK data ${ }^{1}$ and Keeton-Stolk (2008) reports two significant lags employing South African data.

The significance of the lags could be interpreted as evidence of habit in the purchasing decision of agents. Farrell et al. (1999) explicitly base the functional form they estimate on the "rational addiction" model of Becker and Murphy (1988). However, the lag structures reported in their empirical work do not have the form suggested by the Becker and Murphy model. Whilst the Becker and Murphy model illustrates that the structural demand functions of

\footnotetext{
* Corresponding author.

E-mail address: i.mchale@salford.ac.uk (I.G. McHale).

1 The LM test for serial correlation of order (2,3 and 4) suggests higher order serial correlation in the residuals of the regression results reported by Farrell et al. (1999) for the UK which were based on a shorter data set than that employed by Forrest et al. (2000).
}

individuals can be autoregressive it does not necessarily follow that the aggregate demand curve will also exhibit the same autoregressive structure. Granger (1980) demonstrates how aggregation over heterogeneous agents, who exhibit different degrees of habit or autoregressive parameters, can generate a function which exhibits the fractional property. A fractional process exhibits an autocorrelation function that exhibits hyperbolic rather than geometric decay and consequently the aggregate function has different properties to that of any individual in the aggregate.

These results on aggregation are of more than theoretical interest since fractional processes can exhibit, like I(1) processes, the 'spurious regressions' problem with important implications for the appropriate methods for analyzing aggregate relationships ${ }^{2}$ (see, for example, Marmol, 1998, Davidson, 2002, and Sun, 2006).

Our purpose in this letter is to determine whether two series of aggregate lottery sales in the UK exhibit the fractional property. The letter is structured as follows. In Section 2 we set briefly set out the models that can generate aggregate fractional behavior. Section 3 sets out our method of estimation, data and empirical results. The final section provides a brief conclusion.

\footnotetext{
${ }^{2}$ A great variety of empirical work has demonstrated the importance of the central idea of heterogeneous habit at the micro level in analyzing aggregate data. For example, Byers, Davidson and Peel (1997) show that opinion polls on voting intentions exhibit the fractional property. Gras, Frances and Oohms (2003) show that annual theatre ticket sales in Rotterdam exhibit the fractional property. Byers, Peel and Thomas (2007) demonstrate that television audience figures follow a fractional process.
} 


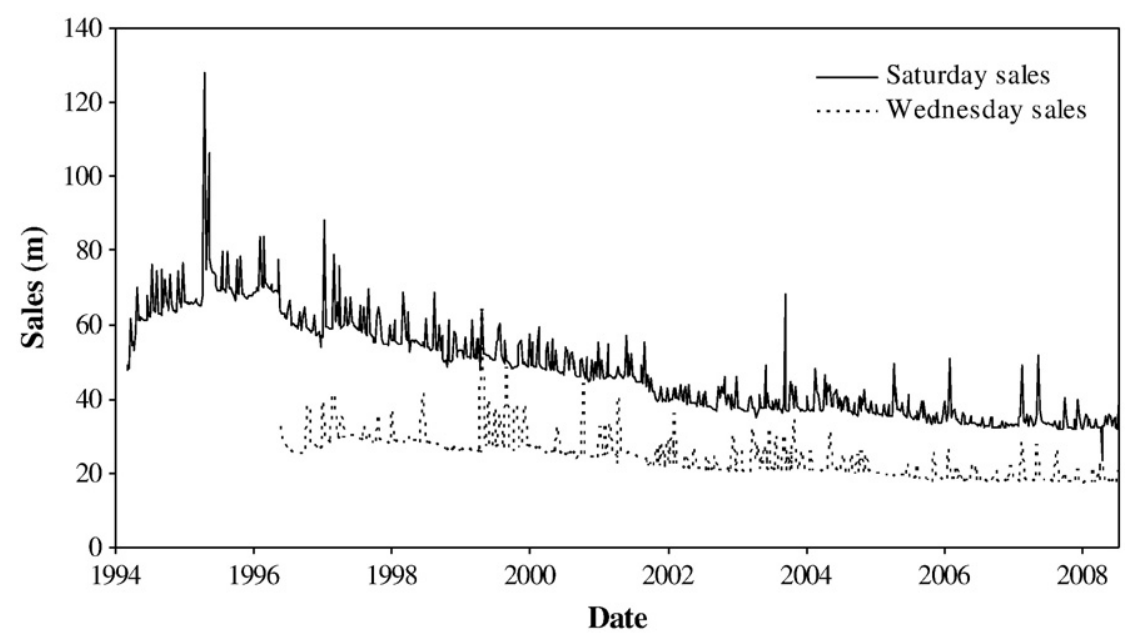

Fig. 1. UK Lotto sales.

\section{Why lottery sales might be fractionally integrated process}

A fractionally integrated process denoted $\operatorname{ARFIMA}(p, d, q)$ has the following form

$x_{t}=(1-L)^{-d} u_{t}$

where $u_{t}$ is a stationary ARMA $(p, q)$ process, and $d$ is a non-integer. A fractionally integrated process is one that exhibits long memory, with persistent local trends, but which nonetheless eventually 'reverts to the mean'. The degree of persistence is measured by a real-valued parameter $d$, lying on the unit interval. At the one extreme, $d=0$ represents the short memory case. If $d>0.5$, the process is not widesense stationary, having infinite variance. And at the other extreme, $d=1$ corresponds to the ordinary integrated process, familiarly known as a random walk. The autocorrelation function of a fractional process decays hyperbolically rather than geometrically and lies between that of a stationary autoregressive model and a unit root process.

Suppose the structural equation derived from the utility function of an agent $(j)$ has the following form

$x_{j, t}=\alpha_{j} x_{j, t-1}+y_{j, t}+\delta_{j} W_{t}+\varepsilon_{j, t}$

where the series $y_{j, t}, W_{t}$ and $\varepsilon_{j, t}$ are independent of each other with the latter white noise and $\alpha$ and $\delta$ are constant for each agent. Granger (1980) demonstrates that the aggregate series, $x_{t}=\sum_{j=1}^{J} x_{j, t}$ derived by aggregating over the $J$ agents' dynamic structural equations will be integrated of order $d$ if the $\alpha_{j}$ are drawn from a $\beta$ distribution over the range ( 0 to 1$)$ with a probability mass of zero at unity. The size of $d$ is affected by the order of integration of the $y$ and $W$ processes but $x_{t}$ is fractionally integrated even if these are $\mathrm{I}(0)$.

An alternative approach to aggregation, which also appears relevant in this context, is the model of Willinger (1995) and Taqqu et al. (1997) who consider a stochastic mechanism which generates a sequence of ones - the source is switched ON (in our context agents purchase a lottery ticket), and zeros - the source is switched OFF (agents do not purchase a lottery ticket). Taqqu et al. analyze the case where the ON and OFF periods alternate with independent and identically distributed lengths, though with possibly different distributions, and show that aggregation of a large number of such series may be fractionally integrated. The crucial condition is that the upper tails of the distribution functions, $F_{i}(x)=\mathrm{ON}$, OFF, of the ON and OFF periods decline in accordance with a 'power law', i.e. $1-F_{i}(x)$ behaves like $x^{-\alpha_{i}}$ as $x \rightarrow \infty$ with $1<\alpha_{i}<2$. As a result there are non negligible probabilities of very long ON and OFF periods.
The type of micro behavior required by this route to aggregation appears relevant to lottery purchases. Whilst a high percentage of agents in many countries gamble on the national lottery at least once a year (around 75\%), the participation rate in a given week can be around 40\% (see, for example, British Gambling Prevalence Survey, 2007). It is easy to imagine that some agents will have very long ' $O N$ ' periods whilst others will have long 'OFF' periods, as required by this route to an aggregate fractional process.

\section{Data and empirical results}

Our data set consists of sales figures for the UK National Lottery game, Lotto for the period 19th November 1994 to 28th March 2009. Initially, prize draws took place on Saturday nights but from 2nd February 1997 a second draw took place on a Wednesday night. As can be seen in Fig. 1 the Wednesday draws attract lower sales.

Fig. 2 shows the autocorrelation function for the residuals ${ }^{3}$ of (a) the de-trended Saturday log-sales obtained from column (1) of Table 1, and (b) the de-trended Wednesday log-sales from column (1) of Table 2. Both demonstrate the slower-than-exponential, hyperbolic decay, suggesting the presence of a fractional series.

Dickey-Fuller tests on the de-trended series reject the null hypotheses of unit roots in both Saturday and Wednesday sales ( $p$-values 0.01 and 0.01 respectively).

Next, we estimate the value of $d$ and to evaluate the robustness of our results we consider three different cases. First, we estimate $d$ both from the 'raw' series (column (2) of Tables 1 and 2) and from the detrended series (column (3) of Tables 1 and 2). Second, we estimate $d$ allowing for non-zero $p$ and $q$ components of the autoregressive and moving average nature of the time series as reported in column 4 of Tables 1 and 2. Finally, we estimate the fractional models at different levels of aggregation to examine whether the result of Chambers (1998), proposition 2, that $d$ should be invariant to time aggregation, holds here. Summaries of the fitted models for log (Saturday sales) and $\log$ (Wednesday sales) are given in columns two to four of Tables 1 and 2 respectively. 4

\footnotetext{
${ }^{3}$ Significant covariates used in the models are: week, a trend variable indicating the week number since the first draw, rollover, a dummy variable indicating that the previous jackpot was not won and was added to the current jackpot, guarantee $£ 15 \mathrm{~m}$, a dummy variable for the fifteen occasions on which the jackpot was guaranteed to be at least $£ 15 \mathrm{~m}$ (on every occasion this meant the lottery operator added funds to the jackpot prize), top up $£ 9.9 \mathrm{~m}$, a dummy variable for the draw when the standard jackpot was boosted by an additional $£ 9.9 \mathrm{~m}$, and first doubles, a dummy variable for the first two double rollovers.

${ }^{4}$ Researchers typically do not deflate sales by the Retail Price Index to obtain real sales. We estimated all regressions and the results were qualitatively similar.
} 
(a)

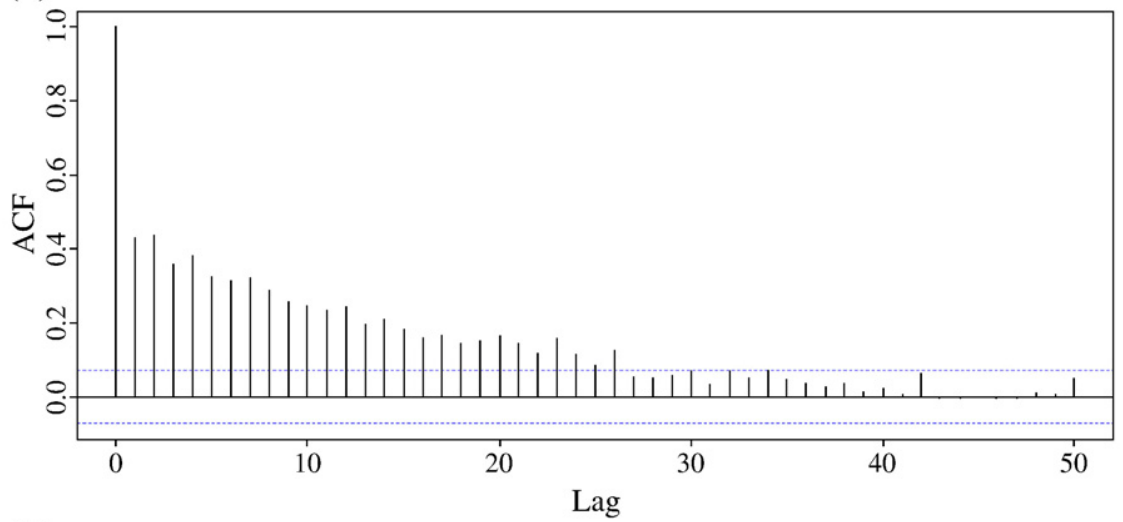

(b)

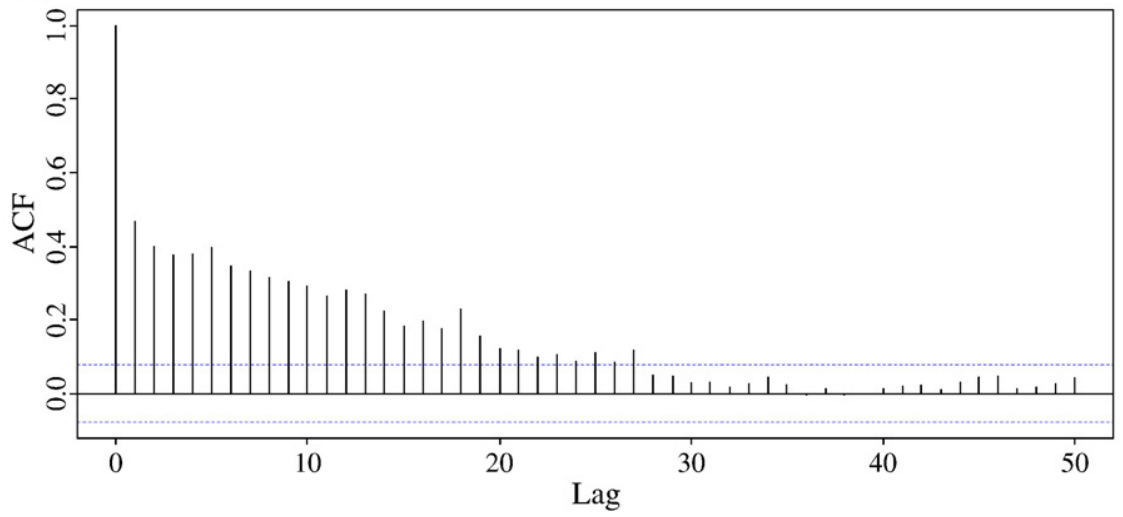

Fig. 2. Autocorrelation function for (a) de-trended Saturday log-sales and (b) de-trended Wednesday log-sales.

The models were fitted using maximum likelihood estimation routines available as part of Ox software (Doornik, 2002) and the ARFIMA package, detailed in Doornik and Ooms (2003). All the estimated models reported in Tables 1 and 2 show significant evidence of a fractional process generating both Saturday and Wednesday sales. The specifications were parsimonious in that the regression residuals appeared free of autocorrelation and ARCH on the basis of the test statistics. Estimation of the models separately for the Saturday and Wednesday models suggests that $d$ is stable around a point value of $0.46-0.50$, a result consistent with the analysis of Chambers (1998) on systematic sampling of a $d$ process. Further, results suggest that the estimated value of $d$ is invariant to time aggregation, complying with Chambers (1998) again. For models (2)

Table 1

Estimation summaries for $\log ($ Saturday sales).

\begin{tabular}{lllll}
\hline & $(1)$ & $(2)$ & $(3)$ & $(4)$ \\
\cline { 2 - 5 } & OLS & $0, \mathrm{~d}, 0$ & $0, \mathrm{~d}, 0$ & $1, \mathrm{~d}, 0$ \\
\hline Week & $-0.000588^{* * *}$ & & $-0.000476^{* * *}$ & $-0.000526^{* * *}$ \\
$\begin{array}{l}\text { Rollover } \\
\quad \text { dummy }\end{array}$ & $0.0988^{* * *}$ & & $0.0984^{* * *}$ & $0.101^{* * *}$ \\
Guarantee & $0.0392^{* *}$ & & & \\
$\quad$ £15 m & & & $0.0482^{* * *}$ & $0.0448^{* * *}$ \\
Top up £9.9 m & $0.294^{* * *}$ & & $0.175^{* * *}$ & $0.178^{* * *}$ \\
First doubles & $0.501^{* * *}$ & & $0.357^{* * *}$ & $0.375^{* * *}$ \\
AR-1 & & & & $-0.294^{* * *}$ \\
d & & $0.484^{* * *}$ & $0.460^{* * *}$ & $0.497^{* * *}$ \\
Constant & $18.01^{* * *}$ & & & \\
LL & 854.55 & 794.03 & 1021.01 & 1051.24 \\
N & 750 & 750 & 750 & 750 \\
AIC & -2.265 & -2.112 & -2.704 & -2.782 \\
\hline
\end{tabular}

*** Statistically significant from zero, $1 \%$ level.

** Statistically significant from zero, $5 \%$ level. to (4) of Tables 1 and 2, the ARCH test of Hendry and Doornik (1999) rejected heteroskedasticity. There is some evidence of residual serial correlation but the AIC suggests the models reported are the most parsimonious.

\section{Conclusion}

On the basis of an aggregation argument when gamblers exhibit different degrees of habit in purchasing decisions it is feasible that aggregate lottery sales could be modeled as a fractionally integrated process. We test this hypothesis using weekly lottery sales from the UK. Our results suggest that lottery sales exhibit the fractional property.

This property has implications for the appropriate method for estimating parameters such as the price elasticity of sales. Because expected price is a nonlinear function of sales it will also exhibit the fractional property as will estimates of higher central moments (see

Table 2

Estimation summaries for $\log ($ Wednesday sales).

\begin{tabular}{lllll}
\hline & $(1)$ & $(2)$ & $(3)$ & $(4)$ \\
\cline { 2 - 5 } & OLS & $0, \mathrm{~d}, 0$ & $0, \mathrm{~d}, 0$ & $1, \mathrm{~d}, 0$ \\
\hline Week & $-0.00475^{* * *}$ & & $-0.000363^{* * *}$ & $-0.000426^{* * *}$ \\
Rollover & $0.287^{* * *}$ & & $0.294^{* * *}$ & $0.294^{* * *}$ \\
$\quad$ dummy & & & & $-0.202^{* * *}$ \\
AR-1 & & & & $0.493^{* * *}$ \\
d & & $0.365^{* * *}$ & $0.456^{* * *}$ & \\
Constant & $17.289^{* * *}$ & & & 899.18 \\
LL & 786.38 & 455.88 & 888.12 & 634 \\
N & 634 & 634 & 634 & -2.821 \\
AIC & -2.471 & -1.432 & -2.789 & \\
\hline
\end{tabular}

$* * *$ Statistically significant from zero, $1 \%$ level. 
Dittmann and Granger, 2002). Consequently the methods of estimation set out by Davidson (2002) on fractional cointegration are indicated. However this is an issue for future research.

\section{References}

British Gambling Prevalence Survey, 2007. National Centre for Social Research. http:// www.gamblingcommission.gov.uk/UploadDocs/publications/Document/Prevalence\%20Survey\%20final.pdf.

Becker, G.S., Murphy, K.M., 1988. A theory of rational addiction. Journal of Political Economy 96, 677-700.

Beenstock, M., Haitovsky, Y., 2001. Lottomania and other anomalies in the market for lotto. J. Econ. Psychol. 22, 721-744.

Byers, D., Davidson, J., Peel, D., 1997. Modelling political popularity: an analysis of long range dependence in Opinion Poll series. Journal of the Royal Statistical Society Series 3 (160), 471-490.

Byers, D., Peel, D.A., Thomas, D., 2007. Habit, aggregation and long memory: evidence from television audience data. Appl. Econ. 39 (3), 321-327.

Chambers, M.J., 1998. Long memory and aggregation in macroeconomic time series. Int. Econ. Rev. 39, 1053-1072.

Cook, P.J., Clotfelter, C.T., 1993. The peculiar scale economies of Lotto. Am. Econ. Rev. 83 (3), 634-643.

Davidson, J., 2002. A model of fractional cointegration, and tests for cointegration using the bootstrap. J. of Econometrics 110 (2), 187-212.

Dittmann, I., Granger, C.W.J., 2002. Properties of nonlinear transformations of fractionally integrated processes. J. of Econometrics 110 (2), 113-133.
Doornik, J.A., 2002. Object-Oriented Matrix Programming Using Ox, 3rd ed. Timberlake Consultants Press and Oxford, London. www.doornik.com.

Doornik, J.A., Ooms, M., 2003. Computational aspects of maximum likelihood estimation of autoregressive fractionally integrated moving average models. Comput. Stat. Data Anal. 41, 333-348.

Farrell, L., Morgenroth, E., Walker, I., 1999. A time series analysis of U.K. lottery sales: long and short run price elasticities. Oxf. Bull. Econ. Stat. 61 (4), 513-526.

Forrest, D., Gulley, O.D., Simmons, R., 2000. Elasticity of demand for UK National Lottery tickets. National Tax Journal 53 (4), 853-864.

Granger, C.W.J., 1980. Long memory relationships and the aggregation of dynamic models. J. of Econometrics 14, 227-238.

Gras, H., Franses, P.H., Ooms, M., 2003. Did men of taste and civilization save the stage? Theater-going in Rotterdam, 1860-1916: a statistical analysis of ticket sales. Journal of Social History 36 (3), 615-655.

Hendry, D.F., Doornik, J.A., 1999. Empirical Econometric Modelling using PcGive: Volume I. Timberlake Consultants Press, London.

Keeton-Stolk, L., 2008. The Economics of Demand for South African Lotteries. Wits University, South Africa.

Marmol, F., 1998. Spurious regression theory with non-stationary fractionally integrated processes. J. of Econometrics 84, 233-250.

Sun, Y., 2006. Spurious regressions between stationary long memory processes. Economics Letters 90, 446-454.

Taqqu, M.S., Willinger, W., Sherman, R., 1997. Proof of a fundamental result in selfsimilar traffic modelling. Computer Communications Review 27, 5-23.

Walker, I., Young, Y., 2001. An economist's guide to lottery design. Econ. J. 111, 700-722.

Willinger, W., Taqqu, M.S., Leland, W.E., Wilson, D.V., 1995. Self-similarity in highspeed internet traffic measurements. Statistical Science 10, 67-85. 